\title{
Avaliação do Desempenho Ambiental do Aproveitamento do Biogás em Fecularias de Mandioca no Estado do Paraná
}

\author{
Celso Eduardo Guimarães ${ }^{1}$ \\ Cláudia Echevenguá Teixeira ${ }^{2}$ \\ Cláudia Brito Silva Cirani ${ }^{3}$ \\ Mario Roberto dos Santos ${ }^{4}$
}

http://dx.doi.org/10.21527/2237-6453.2017.39.171-202

\section{Resumo}

0 processo produtivo da mandioca gera resíduos com altas cargas orgânicas e componentes tóxicos. As indústrias desse setor tratam esses resíduos, na maioria das vezes, em lagoas de estabilização anaeróbias, nas quais se forma o biogás, um gás poluente que, se liberado para a atmosfera de forma indiscriminada, pode impactar no efeito estufa. 0 biogás, entretanto, pode ser recuperado dessas lagoas por meio da tecnologia de biodigestores e, por sua vez, aproveitado para alimentar as caldeiras em substituição à lenha nessas indústrias, gerando energia e diminuindo os impactos ao meio ambiente. 0 artigo tem, então, como objetivo, avaliar o desempenho ambiental da tecnologia de aproveitamento energético de biogás em indústrias processadoras de mandioca paranaenses, por

\footnotetext{
${ }^{1}$ Mestre em Administração na área de concentração de Gestão Ambiental e Sustentabilidade da Universidade Nove de Julho (Uninove). Bacharel em Matemática com ênfase em Ciência da Computação pelo Centro Universitário Fundação Santo André. celsoeduardo.guimaraes@gmail.com

2 Doutora em Engenharia Civil e Ambiental pela Universidade de Sherbooke, Canadá. Mestre em Engenharia Civil, área de concentração em recursos hídricos e saneamento pela Universidade Estadual de Campinas (Unicamp). Bióloga pela Universidade de Caxias do Sul (UCS). Pesquisadora do Instituto de Pesquisas Tecnológicas do Estado de São Paulo (IPT). cteixeira@ipt.br

3 Doutora em Economia Aplicada pela Escola Superior de Agricultura Luiz de Queiroz/Universidade de São Paulo (Esalq/USP). Mestre em Economia Aplicada pela Universidade Federal de Viçosa (UFV). Graduada em Economia pela Universidade Estadual de Londrina (UEL). Professora do Programa de Pós-Graduação em Administração da Universidade Nove de Julho (Uninove). claudiabscirani@gmail.com

4 Doutor em Administração pelo Programa de Pós-Graduação em Administração da Universidade Nove de Julho (Uninove). Mestre em Ciências Contábeis pela Fundação Escola de Comércio Álvares Penteado (Fecap). Graduado em Engenharia Elétrica, modalidade Eletrônica, pela Escola de Engenharia Mauá do Instituto Mauá de Tecnologia (IMT). mario.rsantos@terra.com.br
} 
meio de oito indicadores selecionados a partir do protocolo da Global Reporting Initiative(GRI). Foram escolhidos indicadores relacionados aos aspectos: consumo de materiais, emissões atmosféricas, consumo de água e de energia e emissão de efluentes. Assim, o método de pesquisa foi qualitativo, com utilização de valores quantitativos para os indicadores de desempenho em estudo de casos em três fecularias paranaenses. As principais conclusões deste trabalho sugerem que 0 sistema de aproveitamento de biogás apresenta vantagens ambientais positivas, tais como diminuição de uso de lenha pelas empresas e redução das emissões atmosféricas de gases de efeito estufa. Uma das empresas economizou 95\% de lenha e em todos os casos houve melhoria de desempenho operacional das organizações avaliadas. A pesquisa mostrou que 0 aproveitamento de biogás em operações de agronegócios é uma iniciativa inovadora e apresentou resultados práticos expressivos.

Palavras-chave: Avaliação de desempenho ambiental. Biogás. Ecoinovação. Indicadores de desempenho ambiental. Inovação.

\title{
ENVIRONMENTAL PERFORMANCE EVALUATION BY GRI INDICATORS
}

\begin{abstract}
The production of cassava process generates waste with high organic loads and toxic components. The industries in this sector deal with this waste, most of the time in anaerobic stabilization ponds where they form biogas, a pollutant gas that is released into the atmosphere indiscriminately, can impact on the greenhouse effect. However, the biogas can be recovered these ponds through biodigester technology and, in turn, tapped to feed the boilers to replace firewood in these industries, generating energy and reducing impact on the environment. This article was then assess the environmental performance of energy use of biogas technology in cassava processing industries of Paraná, through selected eight indicators from the Global Reporting Initiative protocol (GRI). Indicators were selected aspects related to material consumption, atmospheric emissions, water consumption, energy consumption and emission of effluents. Thus, the research method was qualitative, using quantitative values for performance indicators in case studies in three potato starch manufacturers Paraná. The main results of this study suggest that the use of biogas system has positive environmental benefits such as decreased use of firewood businesses and reducing atmospheric emissions of greenhouse gases. One company saved $95 \%$ of wood and in all cases; there was improvement in operating performance of the companies evaluated. Research has shown that the use of biogas in agribusiness operations is an innovative initiative and presented significant practical results.
\end{abstract}

Keywords: Environmental performance evaluation. Eco-innovation. Biogas. Environmental performance indicators. Innovation. 
As preocupações do agronegócio em relação à pauta ambiental ainda são tímidas, ou às vezes inexpressivas, quando comparadas com as relacionadas à pauta econômica. De um modo geral, as atividades empresariais típicas (investimentos, produção, estratégias de marketing, entre outras) têm ignorado os danos provocados ao meio ambiente e o esgotamento, quase que irreversível, dos recursos naturais causados por essas ações (STOCGHETTI, 2012).

O senso comum sobre sustentabilidade empresarial é o de minimizar o impacto das atividades da empresa no meio ambiente sem sacrificar a rentabilidade (STOCCHETTI, 2012). De uma maneira convencional pode ser entendida como a capacidade de gerar recursos para remunerar os fatores de produção, repor os ativos usados e investir para continuar competindo (BARBIERI et al., 2010).

O objetivo de reduzir o impacto ambiental da atividade industrial é amplamente aceito como uma meta a ser alcançada. Muitas empresas orgulham-se de seus produtos "verdes" e práticas de negócios "sustentáveis" (HODGE; OCHSENDORF; FERNÁNDEZ, 2010). Na produção, essas práticas podem variar, desde a substituição de materiais não biodegradáveis por biodegradáveis, reciclagem de produtos, redução do consumo de energia e das emissões atmosféricas. A execução dessas práticas empresariais é feita com maior efetividade quando a redução dos impactos ambientais está associada com o aumento dos lucros para o negócio como um todo (HODGE; OCHSENDORF; FERNÁNDEZ, 2010).

Para Boons, Baumann e Hall (2012), aumentar a sustentabilidade das atividades de produção e de consumo exige avaliar as ações e políticas gerenciais empresariais para além das empresas individualmente e dos consumidores. Ao acompanhar a mudança de posicionamento sobre o processo de Desenvolvimento Regional Sustentável (DRS) proporcionado em parte pela percepção da sociedade, Inácio et al. (2013) constataram que o Estado também influencia este processo e que as políticas se relacionam com as regiões e afetam o DRS. 
Conforme Abramovay (2012), economia verde é diferente de crescimento verde e o que se deve almejar é o uso cada vez menor de matéria, energia, com menos emissões de poluentes, como gases de efeito estufa. Dessa forma, buscam-se processos de produção que causem menos impactos ambientais, racionalizando o uso de matérias-primas, de água, de energia e outros recursos naturais e, consequentemente, redução de emissões.

O desenvolvimento de novos produtos sustentáveis é uma tarefa complexa que requer o equilíbrio sistêmico entre todos os envolvidos, desde a produção até o consumo, os consumidores finais, a comunidade, o governo, que se relacionam durante todo o ciclo de vida dos referidos produtos (MARX; PAULA, 2011). Demajorovic e Maturana (2009) defendem que essa estratégia empresarial deve estar associada a novas tecnologias e procedimentos, voltados à sustentabilidade, pois se tornam fundamentais para o entendimento e a avaliação dos impactos das atividades produtivas.

Segundo Faria e Nogueira (2011, p. 2) “[...] não são apenas os indicadores econômico-financeiros que demonstram a saúde de uma organização, mas sim indicadores de caráter social e ambiental que podem ser analisados no chamado Relatório de Sustentabilidade”. Esses relatórios também são fundamentais para a comunicação entre as organizações e seus stakeholders, com foco no desempenho ambiental e social (MORI JR.; BEST; COTTER, 2014).

O uso de relatórios de sustentabilidade é promovido pela GRI como um caminho para as organizações se tornarem mais sustentáveis, contribuindo para o desenvolvimento sustentável, cujo sistema de informações fornece métricas e métodos para medir e relatar impactos e desempenhos relacionados à sustentabilidade (GLOBAL..., 2014).

Conforme Delai e Takahashi (2008, p. 21): “[...] mensurar a sustentabilidade é imprescindível para inseri-la no processo de decisão de todos os níveis organizacionais. Essa mensuração pode ser feita por meio de índices ou conjunto de indicadores". 
No contexto de sustentabilidade e novas tecnologias, é recente o uso da tecnologia de aproveitamento energético a partir do biogás nas fecularias e farinheiras de mandioca. A tecnologia do biogás pode ser considerada um método de produção de energia inovador, mas seus benefícios necessitam ser medidos e avaliados em relação à tecnologia que está substituindo. Assim, deve-se identificar quais são os benefícios, como a redução da lixiviação, a diminuição de aquecimento, a produção de fertilizantes, etc. (LYBAEK; CHRISTENSEN; KJAER, 2013). Starr et al. (2012) advertem que, apesar do crescente interesse nessas tecnologias, há poucas pesquisas sobre seu impacto ambiental.

Este trabalho teve como finalidade avaliar o desempenho ambiental da tecnologia de aproveitamento energético do biogás em indústrias processadoras de mandioca paranaenses. Para tanto foram utilizados oito indicadores baseados nas diretrizes para elaboração de relatórios de sustentabilidade da GRI. Procurou-se avaliar o desempenho ambiental da tecnologia, possibilitando uma análise dos resultados obtidos do desempenho na dimensão ambiental do desenvolvimento sustentável.

O Estado do Paraná é o principal produtor de mandioca da Região Sul e o segundo no ranking nacional, ficando atrás apenas do Pará. Grande parte do setor é formado por pequenas e médias empresas concentradas no Paraná, Mato Grosso do Sul e São Paulo, conforme a Food and Agriculture Organization of the United Nations - FAO (FOOD..., 2013). Ressalta-se a importância de se estudar o tema, uma vez que tal tecnologia é uma ferramenta que visa a reduzir o impacto ambiental, haja vista que o aproveitamento energético do biogás oferece grande potencial de transformar em energia limpa e sustentável resíduos geradores de gases nocivos ao meio ambiente. Nesse sentido, os resultados deste trabalho, além de fornecerem informações relevantes aos produtores do setor, podem ser essenciais para a formulação de políticas públicas que visem a ampliar o uso da tecnologia como auxílio para a agroindústria diminuir problemas ambientais. 
O trabalho utilizou o método qualitativo, por meio de estudo de casos múltiplos (três) em empresas processadoras de mandioca e foi restrito ao desenvolvimento e implantação do sistema biodigestor.

Este artigo apresenta: a introdução, a fundamentação teórica; o método de pesquisa; os resultados da pesquisa; as considerações finais e as referências bibliográficas.

\section{Fundamentação Teórica}

Nesta seção apresenta-se a descrição da indústria processadora da mandioca, com foco nas farinheiras e nas fecularias, o processo de tratamento de efluentes em lagoas de estabilização, os indicadores de desempenho ambiental e as diretrizes da GRI.

\section{Indústrias Processadoras de Mandioca e Desempenho Ambiental}

A indústria processadora de mandioca avançou significativamente no Brasil graças aos recentes investimentos em pesquisas de algumas universidades brasileiras, com destaque para o Centro Nacional de Pesquisa da Mandioca e Fruticultura em Cruz das Almas, na Bahia, o Instituto Agronômico de Campinas (IAC), a Universidade Estadual de São Paulo (Unesp) de Botucatu e o Instituto Agronômico do Paraná (Iapar) (FELIPE; ALVEZ; CAMARGO, 2010). Para aumentar as receitas destinadas ao financiamento das pesquisas, o Iapar foi em busca de maior competitividade, utilizando-se até mesmo de modelos de gestão empresarial (REZENDE; ICHIKAWA, 2011).

Para a produção de farinha e fécula, a matéria-prima principal (mandioca) utilizada é de uma variedade conhecida como "amarga", ou "mandioca brava". Com alta concentração de ácido cianídrico, essa variedade possui as maiores concentrações de amido, características que garantem boa pro- 
dutividade para as indústrias, entretanto é isso que pode comprometer o desempenho ambiental, devido à toxidade dos resíduos gerados. O produto base desse setor, o amido, é utilizado na produção de medicamentos, alimentos, cosméticos, celulose e na produção têxtil. Ele é exportado para todos os continentes, especialmente Estados Unidos da América (EUA) (35,3\%), Bolívia (21,0\%) e República Dominicana (17,6\%), representando 3,11 mil toneladas do produto exportado em 2011conforme o Centro de Estudos Avançados em Economia Aplicada da Escola Superior de Agricultura Luiz de Queiroz (CENTRO...; ESCOLA..., 2013).

A norma da Associação Brasileira de Normas Técnicas (ABNT) NBR ISO 14001:2004 definiu desempenho ambiental como “[...] os resultados mensuráveis da gestão de uma organização sobre os seus aspectos ambientais" (ASSOCIAÇÃO..., 2004, p. 3). Quanto ao aspecto ambiental, é todo "[...] elemento das atividades ou produtos ou serviços de uma organização que pode interagir com o meio ambiente" (p. 2). Segundo Barbieri (2007), pode ser resultado de usos de matéria-prima, água, energia, entre outros recursos demandados pelos processos produtivos. Pode ainda ser decorrente dos resíduos desse mesmo processo. $\mathrm{O}$ autor definiu “[...] o aspecto ambiental como a causa e o impacto ambiental seu efeito" (BARBIERI, 2007, p. 172). Ou seja, impacto ambiental é o resultado maléfico ou benéfico causado pelo aspecto ambiental de determinado processo produtivo. A definição de impacto ambiental, segundo a norma ISO 14001:2004 é "[...] qualquer modificação do meio ambiente, adversa ou benéfica, que resulte, em todo ou em parte, dos aspectos ambientais da organização" (ASSOCIAÇÃO..., 2004, p. 2).

Dessa forma, a organização que deseje ter um bom desempenho ambiental precisa gerir sua pauta ambiental, por meio de um Sistema de Gestão Ambiental (SGA) formal ou não. Conforme Barbieri (2007), um SGA requer a formulação de diretrizes, definição de objetivos, coordenação de atividades e monitoramento de resultados. Seiffert (2010) apresentou a identificação de aspectos ambientais associados a atividades, processos e produtos da 
organização como uma das fases mais importantes na elaboração do SGA. Nas atividades de fecularias de mandioca o aspecto de geração de resíduos, por conter ácido cianídrico, que é tóxico, tem grande potencial de impacto negativo (FELIPE; RIZATO; WANDALSEN, 2009).

Cunico, Cirani e Souza (2012), em recentes pesquisas em fecularias, observaram que as indústrias do setor vêm se preocupando em entender e gerenciar seus aspectos e impactos ambientais. Dessa forma, buscam o uso de práticas tecnológicas que suportem suas operações de forma a atender à legislação ambiental, principalmente em relação à geração de resíduos.

Os resíduos mais relevantes são derivados dos processos de lavagem, descascamento, ralação e prensagem da mandioca (CAMPOS, 2006). Essas fases geram grandes quantidades de resíduos orgânicos, com destaque para a manipueira - água que carrega a maioria dos solúveis presentes nas raízes - incluindo a linamarina, que são rejeitados nas fases de produção de farinha e fécula de mandioca (OLIVEIRA; IDE; PAULO, 2005). A manipueira é um dos resíduos mais problemáticos nas fecularias, em termos ambientais, por possuir elevadas cargas de poluentes (BARANA; CEREDA, 2000).

Nesse cenário, o tratamento por processos biológicos, do ponto de vista econômico, por sua simplicidade, é o que tem se mostrado mais eficiente. Entre eles destaca-se o tratamento por meio de lagoas de estabilização, utilizando processos anaeróbios para remoção de matéria orgânica.

\section{Tratamento de Efluentes em Lagoas de Estabilização Anaeróbias}

Os efluentes das indústrias de fecularias de mandioca são ricos em matéria orgânica. Os poluentes orgânicos presentes na fase aquosa, quando despejados nos sistemas hídricos em grandes concentrações, alteram significativamente os aspectos físico-químicos do meio ambiente, interferindo nas condições ambientais que suportam a biodiversidade nativa daquele meio (CREMONEZ et al., 2013; SANT'ANNA JR., 2010). A manipueira 
evidencia seu potencial poluidor, em função das concentrações elevadas em termos de demanda química e demanda bioquímica de oxigênio (DQO e DBO), nutrientes (nitrogênio e fósforo), substâncias tóxicas (cianetos) e material particulado (sólidos).

Os sistemas anaeróbios de tratamento de efluentes caracterizam-se como um processo de biodegradação da matéria orgânica que ocorre mais lentamente, quando comparado com sistemas de tratamento aeróbios (SAN'T'ANNA JR., 2010).

Devido ao alto custo de energia necessária para promover a aeração, as fecularias optam por sistemas de tratamento por processos anaeróbios em lagoas, que têm poucas exigências quanto a requisitos de construção, mostrando-se uma opção atrativa do ponto de vista econômico (PARIZOTTO, 2002). São feitas por meio de escavação em terrenos, impermeabilizadas com argila ou manta plástica, cujas bordas devem ser reforçadas a fim de diminuir riscos de desmoronamento e vazamentos.

O biodigestor, presente no processo, é constituído por uma câmara na qual ocorre a acumulação de gás (SEIXAS; FOLLE; MARCHETTI, 1980). Os materiais orgânicos depositados na câmara são consumidos por bactérias anaeróbias. Esse processo de consumo do material orgânico por bactérias anaeróbias resulta no biogás e nos restos digeridos (sem odor). Os resíduos digeridos podem ser utilizados na agricultura como fertilizantes, devido ao elevado conteúdo de nutrientes (FUCHS; DROSG, 2013). Essa tecnologia também vem sendo adotada na gestão de resíduos em aterros sanitários e tratamento de águas residuais (STARR et al., 2012).

Para aproveitamento do biogás gerado nas lagoas de estabilização, algumas fecularias estão instalando uma manta sobre a lagoa. Dessa forma é criado um sistema de biodigestor, com a câmara formada por essa cobertura.

Uma característica do gás metano $\left(\mathrm{CH}_{4}\right)$, principal componente do biogás, é o poder de aquecimento molecular, que resulta em alta absorção de radiação solar na atmosfera terrestre, constituindo um potente causador 
de efeito estufa. Queimá-lo antes de ser liberado na atmosfera, portanto, já torna a atividade produtiva menos poluente, mesmo que não seja aproveitado o seu potencial energético por meio da liberação de calor. Essa queima tem a possibilidade de melhorar a sustentabilidade das operações de indústrias processadoras de mandioca, diminuindo emissões de gases do efeito estufa (GEEs) e economizando recursos financeiros com o aproveitamento da energia calorífica dessa queima, seja para gerar eletricidade, seja para substituir outros combustíveis, como a lenha.

\section{Indicadores de Desempenho Ambiental}

Os indicadores de desempenho ambiental servem como parâmetro para analisar se as emissões estão dentro dos padrões exigidos pela legislação, assim como se esses e outros aspectos produtivos obedecem às normas ambientais internas das empresas, estabelecidas por um plano de objetivos e metas. Os indicadores são também usados para que a comunidade afetada pelas atividades (comunidade do entorno, clientes, acionistas, entre outros) acompanhe o desempenho de uma organização (GALLOPÍN, 1997; SEIFFFERT, 2010; SERVIÇO..., 2003).

Para este estudo foram utilizados os conceitos dos indicadores de efluentes e emissões atmosféricas de GEEs, tendo em vista o objetivo do trabalho: avaliação da instalação de biodigestores nas lagoas de estabilização para captação de biogás. Para atingir o objetivo do trabalho, oito indicadores preconizados pelas Diretrizes GRI na dimensão ambiental foram utilizados.

A GRI foi criada em 1997 em Boston, nos EUA, tendo suas raízes nas organizações sem fins lucrativos da Coalition for Environmentally Responsible Economies (Ceres) e no Tellus Institute (GLOBAL..., 2014). O objetivo foi criar diretrizes aplicáveis à elaboração de relatórios sobre o desempenho econômico, ambiental e social e garantir que as empresas seguissem os Príncipios Ceres de conduta ambiental responsável, tendo como público-alvo os investidores (GLOBAL..., 2014; HEDBERG; VON MALMBORG, 2003). 
Os indicadores criados para elaboração dos relatórios da GRI dividem-se em três blocos, segundo a abordagem do triple bottom line: econômico, ambiental e social (GLOBAL..., 2006b).

As Diretrizes GRI (2006b) recomendam que, em relação aos indicadores ambientais, as organizações devem abordar seu desempenho relativo a consumo de insumos (material, energia e água) e os aspectos relativos às emissões (atmosféricas, efluentes e resíduos) derivadas de seus processos produtivos. A apresentação dos indicadores de desempenho ambiental da GRI baseia-se na eficiência de consumo, influência na biodiversidade e na minimização de impactos (SILVA; SIQUEIRA; GOMES, 2010). Araujo e Oliveira (2008) destacam que os indicadores de sustentabilidade GRI é uma das ferramentas importantes no mercado para medição de desempenho de sustentabilidade em operações de manufatura. Os autores (2008) frisaram a importância de, uma vez definidos os principais aspectos e impactos da organização, escolher um modelo de indicadores que contemplem os principais pontos de pressão dos processos a serem avaliados.

Os indicadores de sustentabilidade sugeridos pelas diretrizes GRI são utilizados para suportar os relatórios das organizações. Neste estudo utilizou-se a mesma estrutura para avaliar os biodigestores instalados em lagoas de estabilização para tratamento de efluentes das agroindústrias da cadeia produtiva de mandioca.

\section{Método}

Para esta pesquisa em questão utilizou-se o método qualitativo, por meio de estudo de casos múltiplos (três) em empresas processadoras de mandioca: duas fecularias e uma farinheira de mandioca da região oeste do Paraná. Uma empresa de Engenharia, a Planotec, participou também do projeto, colaborando com a coleta de dados nas empresas pesquisadas, fornecendo as informações sobre o sistema de biodigestores por ela desenvolvido. 
O trabalho desta pesquisa foi restrito ao desenvolvimento e instalação do sistema de biodigestor, que aproveita o biogás produzido em lagoas de estabilização para tratamento de efluentes das indústrias, utilizando-o nas próprias caldeiras das empresas processadoras de mandioca.

A seleção das empresas pesquisadas considerou a importância de se avaliar a tecnologia em mais de uma organização para fins de comparação em escalas de processamento, tecnologia e estruturas organizacionais diferentes. Desta forma, três empresas foram convidadas a participar desta pesquisa.

As informações foram coletadas por meio dos seguintes procedimentos:

a) Entrevistas e visitas in loco com os responsáveis pela operação das indústrias para coleta e registro das observações. As entrevistas foram realizadas no mês de agosto de 2013, nas instalações das três indústrias processadoras de mandioca.

b) Algumas questões não respondidas totalmente durante as entrevistas ou que necessitavam de levantamento histórico de dados foram respondidas por intermédio de trocas de correio eletrônico com os gestores em setembro de 2013.

c) Entrevistas com os proprietários da empresa de projetos de biodigestores Planotec.

d) Coleta de amostras e análises in loco da composição físico-química do biogás das três indústrias processadoras de mandioca, com medições efetuadas pela Planotec por meio de um analisador de gás portátil industrial para medições em aterros sanitários (GEM2NAV). O equipamento foi alugado mediante financiamento concedido pela Coordenação de Aperfeiçoamento de Pessoal de Nível Superior (Capes). O fornecedor do equipamento foi a empresa Landtec, do município de São Paulo. 
Para medir o fluxo de gás foi alugado o equipamento tubo de Pitot que é utilizado pela Planotec em conjunto com o GEM2NAV. Segundo Jahn, Dadam e Nicolau (2006, p. 3), "o tubo de Pitot fornece uma medida de pressão dinâmica do escoamento; com a pressão estática e a temperatura do ponto medido, estima-se a densidade dos gases e calcula-se a vazão mássica".

Visando a estabelecer indicadores para avaliação de desempenho ambiental da tecnologia em questão, partiu-se dos indicadores de desempenho GRI na esfera ambiental segundo suas diretrizes na versão G3.1. A partir da análise de conteúdo de cada indicador e das características do processo de aproveitamento de biogás das três indústrias, foram identificados e selecionados aqueles com possibilidade de serem aplicados, bem como a métrica que permitiu abastecer cada um deles com o ojetivo de avaliar o desempenho ambiental do aproveitamento de biogás em biodigestores no tratamento de efluentes do processo de produção de fécula farinha de mandioca.

Os oito indicadores selecionados estão apresentados no Quadro 1.

Quadro 1 - Indicadores de desempenho ambiental GRI selecionados

\begin{tabular}{|c|l|l|}
\hline Código & \multicolumn{1}{|c|}{ Aspecto ambiental } & \multicolumn{1}{c|}{ Título } \\
\hline EN1 & Consumo de Materiais & Materiais usados por massa e volume \\
\hline EN3 & Consumo de Energia & $\begin{array}{l}\text { Consumo de energia direto por fonte de energia } \\
\text { primária }\end{array}$ \\
\hline EN5 & Consumo de Energia & $\begin{array}{l}\text { Energia economizada devido a melhorias em conserva- } \\
\text { ção e eficiência }\end{array}$ \\
\hline EN8 & Consumo de água & Total de água retirada por fonte \\
\hline EN16 & Emissões Atmosféricas & $\begin{array}{l}\text { Total de emissões diretas e indiretas de gases de efeito } \\
\text { estufa, por massa }\end{array}$ \\
\hline EN18 & Emissões Atmosféricas & $\begin{array}{l}\text { Iniciativas para reduzir as emissões de gases de efeito } \\
\text { estufa e as reduções obtidas }\end{array}$ \\
\hline EN20 & Emissões Atmosféricas & $\begin{array}{l}\text { NO }, \text { SO } \text { e outras emissões atmosféricas significativas, } \\
\text { por tipo e massa }\end{array}$ \\
\hline EN21 & Efluentes & Descarte total de água, por qualidade e destinação \\
\hline
\end{tabular}

Fonte: Adaptado de Diretrizes GRI (GRI, 2006a). 
A seleção ocorreu a partir do levantamento de aspectos ambientais, mudanças do processo produtivo e validação simplificada com o engenheiro responsável pelo desenvolvimento da tecnologia nas indústrias processadoras de mandioca investigadas.

Quanto às mudanças no processo, as medidas são para a adaptação de processos com o objetivo do aproveitamento energético do biogás. Conforme já se mencionou, as fecularias utilizam lagoas de estabilização anaeróbica para tratamento dos resíduos de produção. Durante o tratamento anaeróbico forma-se o biogás, cuja mistura de gases é composta por grande quantidade de metano - um gás poluente -, que, se liberado para a atmosfera de forma indiscriminada, pode impactar no efeito estufa. O biogás, entretanto, pode ser recuperado dessas lagoas por meio da tecnologia de biodigestores e, por sua vez, aproveitado para alimentar as caldeiras, em substituição à lenha, gerando energia e diminuindo os impactos no meio ambiente, em razão da combustão do metano. A Figura 1 exibe imagens do tratamento de efluentes, antes e depois do aproveitamento do biogás, em uma das três empresas pesquisadas neste trabalho.

Figura 1 - Imagens da lagoa de estabilização anaeróbica de uma das fecularias analisadas -2013

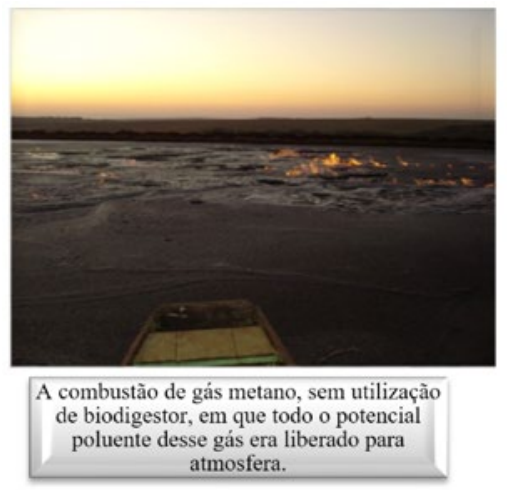

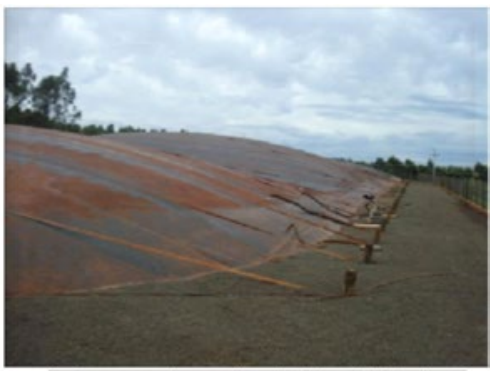

A mesma lagoa depois da instalação do biodigestor, capturando o gás metano para produção de biogás e, consequentemente, aproveitamento na caldeira.

Fonte: Dados da pesquisa. 
Ainda visando a destacar as mudanças tecnológicas do processo, a seguir apresenta-se um fluxograma da cadeia produtiva da mandioca, explicitando, ao lado, algumas alterações no processo de produção após a implantação do biodigestor, especialmente o aproveitamento do biogás e das águas geradas e descartadas a partir da manipulação da mandioca (Figura 2).

Figura 2 - Fluxograma da cadeia produtiva da mandioca

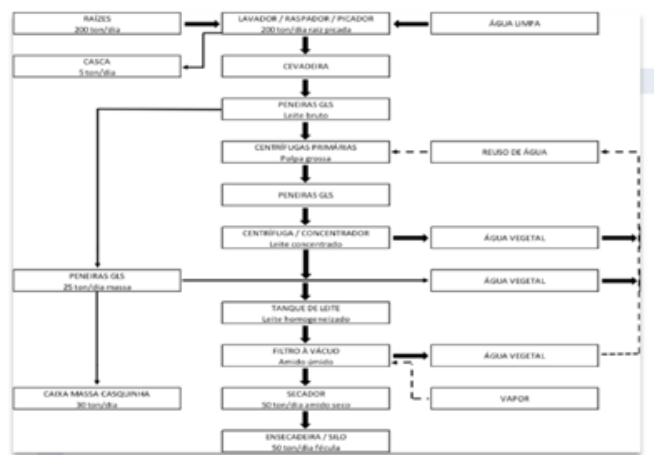

A mesma água que entra limpa na fase de lavar/raspar/picar passa pela cevadeira, peneira GLS, centrifuga, tanque de leite e filtro à vácuo e, agora denominada água vegetal, volta para centrifuga e só depois vai para lagoa anaeróbica.

Antes a água limpa entrava na fase de lavar/raspar/picar, passava por todo o processo da cadeia produtiva e, no

Após a filtração à vácuo o produto é enviado ao secador, cujo calor é gerado pelo biogás produzido durante o tratamento anaeróbico $\mathrm{e}$ queimado na caldeira. Sem o uso do biogás, utilizava-se lenha para geração de calor e secagem da mandioca.

final, ia direto para lagoa.

Fonte: Dados da pesquisa.

\section{Resultados e Análise}

Esta seção apresenta as empresas pesquisadas, os indicadores de desempenho ambiental, os valores quantitativos dos indicadores, discussões e conclusões em relação ao desempenho ambiental do sistema de captação e utilização de biogás produzido a partir de resíduos em unidades processadoras de mandioca.

\section{Empresas Pesquisadas}

As três empresas pesquisadas localizam-se nas regiões Oeste e Noroeste do Estado do Paraná: Amidonaria C. Vale - unidade Assis Chateaubriand; Amidos Pasquini - Cianorte - e Alimentos do Zé - Nova Esperança. 
A Amidonaria C. Vale - unidade Assis Chateaubriand - faz parte de um conglomerado de indústrias agrícolas atuante no Brasil nos Estados do Paraná, Santa Catarina, Mato Grosso e Mato Grosso do Sul e com unidades também no Paraguai. A C. Vale é uma cooperativa com 50 anos de existência, possui 111 unidades de negócios, 14.600 associados e 6.038 funcionários. Seus principais produtos são soja, milho, trigo, mandioca, leite, frangos e suínos. Atua também na prestação de serviços a agricultores e à agroindústria (C. VALE, 2014).

A unidade está localizada em Assis Chateaubriand, produz amido modificado a partir de fécula de mandioca para atender à indústria de papel. A produção média diária de amido modificado é da ordem de 70 toneladas e consumo médio de 400 toneladas de mandioca. Essa foi a primeira indústria na qual a Planotec instalou o sistema de biodigestor, em agosto de 2011.

A Amidos Pasquini é uma empresa produtora de fécula de mandioca principalmente para fins alimentícios. Possui uma estrutura administrativa familiar e foi fundada no ano de 1990 para produção de farinha de mandioca. A partir de 2001 passou a produzir a fécula in natura, tendo como principais clientes as indústrias de alimentos, de papel e têxtil.

Sua produção média diária de fécula é da ordem de 80 toneladas, com consumo médio de mandioca de 265 toneladas. O sistema de biodigestor foi instalado em setembro de 2012 com poucas adaptações e depois de um ano de funcionamento, após o encerramento desta pesquisa, a empresa adquiriu uma nova caldeira, específica para uso do biogás, que previa aumento da capacidade produtiva na ordem de $45 \%$.

A Alimentos do Zé é uma empresa produtora de alimentos à base de mandioca, cujos principais produtos são farinha e polvilho. É uma empresa familiar e está no mercado desde o ano de 1967. A empresa possui campos ao redor da indústria com plantações de eucalipto para produção de lenha, pasto para criação de gado e cultivo de mandioca. A princípio, a empresa cultivava sua própria mandioca para a produção da farinha, mas hoje a maior 
parte da matéria-prima é comprada no mercado. O sistema de biodigestor foi instalado em maio de 2013 e a empresa passou a comercializar a lenha economizada com a utilização do biogás.

A produção diária média é de 53 toneladas de farinha e 5 toneladas de polvilho, consumindo aproximadamente 200 toneladas de mandioca como matéria-prima.

\section{Biodigestores Desenvolvidos pela Empresa Planotec}

A criação do projeto dos biodigestores partiu da ideia de cobrir a lagoa de estabilização utilizada para o tratamento dos efluentes das fecularias e farinheiras. O biogás fica encapsulado no biodigestor, sendo levado até a caldeira por tubulações subterrâneas de PVC. Em determinados pontos da cobertura, canalizou-se o biogás até o ponto de queima da caldeira com mangueiras e encanamentos. Instalou-se um ventilador para forçar o deslocamento do biogás (por exaustão) e uma válvula para controlar o fluxo do gás. Tal inovação permite que não haja desperdício de biogás e que o fogo gerado se apague caso o biogás não tenha força para subir a inclinação do terreno (ocasionando a parada da produção). Outra inovação que surgiu com o aproveitamento do biogás é o acendedor que fica acoplado diretamente na tubulação metálica, permitindo que o biogás seja queimado na própria tubulação, que conduz o calor gerado até o secador, não havendo mais a necessidade de levar o biogás até a caldeira. Dessa forma, com a energia proveniente da queima do biogás, menor quantidade de lenha foi necessária para produzir a energia requerida pelo processo produtivo.

A Figura 3 mostra a redução significativa no uso da lenha depois do aproveitamento do biogás numa das empresas pesquisadas, com destaque para as inovações que surgiram a partir da extração do biogás. A lenha existente no pátio, de acordo com o gestor da empresa, é a sobra da última compra realizada no ano anterior e que estava se deteriorando devido ao clima da região. 
Figura 3 - Sistema de biodigestor com formação de GEE completa e as inovações que surgiram com a instalação do sistema

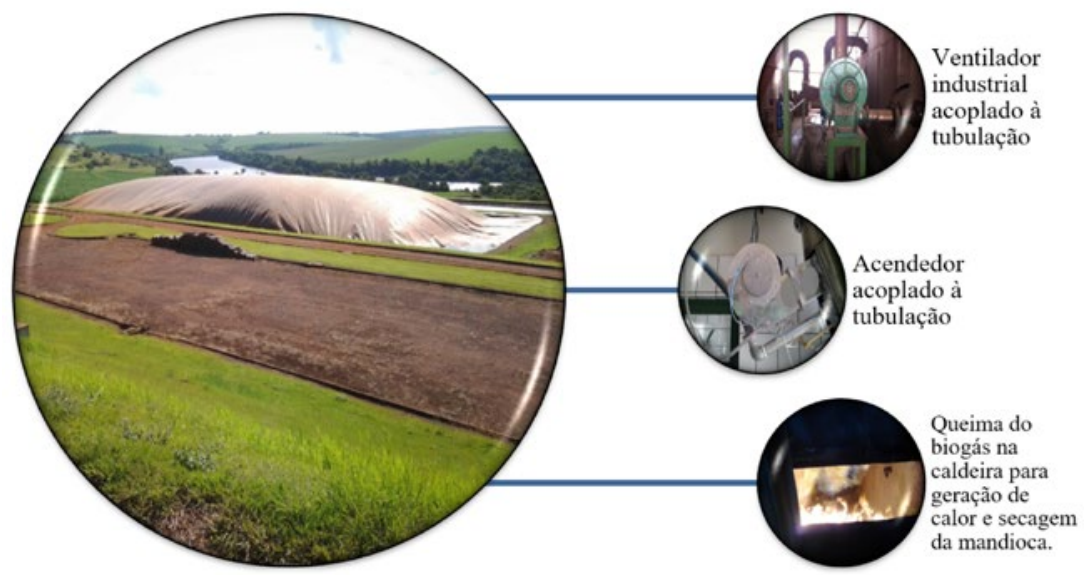

Fonte: Dados da pesquisa.

\section{Critérios de Seleção dos Indicadores Ambientais}

O Quadro 2 apresenta os critérios adotados para seleção dos oito indicadores e suas respectivas justificativas de escolha. Na terceira coluna está a descrição do conteúdo dos indicadores. Para aplicação dos critérios, o primeiro passo foi conhecer os processos e identificar quais aspectos e impactos poderiam ser avaliados. A quarta coluna apresenta as fontes de informações utilizadas para quantificar os indicadores.

Quadro 2 - Critérios e conteúdo dos indicadores GRI de desempenho ambiental

\begin{tabular}{|c|l|l|l|}
\hline Código & Critério para seleção & Conteúdo do Indicador & Fonte de informações \\
\hline \multirow{2}{*}{ EN1 } & $\begin{array}{l}\text { Avaliar a economia do } \\
\text { uso de lenha nos proces- } \\
\text { sos produtivos da indús- } \\
\text { tria com a instalação do } \\
\text { sistema de biodigestor. }\end{array}$ & $\begin{array}{l}\text { Volume médio diário } \\
\text { de lenha utilizado como } \\
\text { insumo nas caldeiras } \\
\text { antes e após a instalação } \\
\text { dos biodigestores por } \\
\text { unidade produzida. }\end{array}$ & $\begin{array}{l}\text { Registros históricos das } \\
\text { empresas fornecidos por } \\
\text { meio de entrevistas com } \\
\text { gestores operacionais. }\end{array}$ \\
\hline
\end{tabular}




\begin{tabular}{|c|c|c|c|}
\hline EN3 & $\begin{array}{l}\text { Apurar a energia con- } \\
\text { sumida com o com- } \\
\text { bustível lenha para } \\
\text { aquecer as caldeiras } \\
\text { antes e depois dos biodi- } \\
\text { gestores. }\end{array}$ & $\begin{array}{l}\text { Energia consumida } \\
\text { (lenha transformada } \\
\text { em potencial energé- } \\
\text { tico - quilocalorias por } \\
\text { quilograma) por massa } \\
\text { de mandioca moída para } \\
\text { o processo produtivo de } \\
\text { farinha e/ou fécula. }\end{array}$ & $\begin{array}{l}\text { Registros históricos das } \\
\text { empresas fornecidos por } \\
\text { meio de entrevistas com } \\
\text { gestores operacionais e } \\
\text { cálculos para transforma- } \\
\text { ção da massa de lenha } \\
\text { consumida em potencial } \\
\text { energético. }\end{array}$ \\
\hline EN5 & $\begin{array}{l}\text { Apresentar de forma } \\
\text { direta a energia econo- } \\
\text { mizada proveniente da } \\
\text { lenha com a utilização } \\
\text { do biogás, que antes era } \\
\text { dissipado diretamente na } \\
\text { atmosfera. }\end{array}$ & $\begin{array}{l}\text { Total de energia derivada } \\
\text { de lenha economizada } \\
\text { com o aproveitamento do } \\
\text { biogás gerado pelos bio- } \\
\text { digestores. }\end{array}$ & $\begin{array}{l}\text { Cálculo da diferença } \\
\text { entre o que se consumia } \\
\text { (em potencial energético } \\
\text { da lenha consumida) } \\
\text { antes e após o aproveita- } \\
\text { mento do biogás produ- } \\
\text { zido por biodigestores. } \\
\end{array}$ \\
\hline EN8 & $\begin{array}{l}\text { Responder à questão se } \\
\text { há influência direta no } \\
\text { consumo de água nos } \\
\text { processos da fecularia } \\
\text { com o sistema de biodi- } \\
\text { gestor. }\end{array}$ & $\begin{array}{l}\text { Água consumida por } \\
\text { toneladas de mandioca } \\
\text { processada antes e depois } \\
\text { dos biodigestores. }\end{array}$ & $\begin{array}{l}\text { Dados históricos dos } \\
\text { registros de produção das } \\
\text { empresas e dos volumes } \\
\text { de água captada obtidos } \\
\text { por entrevistas. }\end{array}$ \\
\hline EN16 & $\begin{array}{l}\text { Avaliar a diminuição das } \\
\text { emissões de GEEs após } \\
\text { a instalação dos biodi- } \\
\text { gestores. }\end{array}$ & $\begin{array}{l}\text { Medição das emissões } \\
\text { no bico do queimador do } \\
\text { biogás. }\end{array}$ & $\begin{array}{l}\text { Medições no local por } \\
\text { meio de equipamento es- } \\
\text { pecífico do biogás gerado } \\
\text { pelo biodigestor. }\end{array}$ \\
\hline EN18 & $\begin{array}{l}\text { Avaliar a diminuição das } \\
\text { emissões de GEEs após } \\
\text { instalação dos biodiges- } \\
\text { tores. }\end{array}$ & $\begin{array}{l}\text { Apresentação das } \\
\text { emissões de } \mathrm{CO}_{2 \mathrm{e}} \text { antes } \\
\text { e após a instalação dos } \\
\text { biodigestores. }\end{array}$ & $\begin{array}{l}\text { Derivação do indicador } \\
\text { utilizando metodologia } \\
\text { IPCC para cálculo de } \\
\mathrm{CO}_{2 \mathrm{e}} .\end{array}$ \\
\hline EN20 & $\begin{array}{l}\text { Apurar as emissões de } \\
\mathrm{H}_{2} \mathrm{~S} \text { provenientes dos } \\
\text { processos de tratamento } \\
\text { de efluentes. }\end{array}$ & $\begin{array}{l}\mathrm{H}_{2} \mathrm{~S} \text { em partes por milhão } \\
(\mathrm{ppm}) .\end{array}$ & $\begin{array}{l}\text { Medições no local por } \\
\text { meio de equipamento es- } \\
\text { pecífico do biogás gerado } \\
\text { pelo biodigestor. }\end{array}$ \\
\hline EN21 & $\begin{array}{l}\text { Avaliar se houve mu- } \\
\text { danças na qualidade da } \\
\text { água com a instalação do } \\
\text { sistema de biodigestores }\end{array}$ & $\begin{array}{l}\text { Serão relatados os indica- } \\
\text { dores de qualidade dos } \\
\text { efluentes na entrada e na } \\
\text { saída dos biodigestores } \\
\text { (DBO, DQO). }\end{array}$ & $\begin{array}{l}\text { Medição em laboratório } \\
\text { credenciado de amostras } \\
\text { de efluentes na entrada e } \\
\text { saída do biodigestor. }\end{array}$ \\
\hline
\end{tabular}

Fonte: Adaptado do GRI (GLOBAL..., 2006a).

Com o conjunto de indicadores selecionado e com as informações colhidas pela pesquisa, construiu-se uma base comparativa entre as três indústrias e para cada empresa, antes e depois do uso dos biodigestores. Os valores relativos ao consumo de matérias-primas como mandioca, água 
e lenha, juntamente com as quantidades produzidas de fécula e farinha de mandioca, tiveram como objetivos possibilitar conclusões quanto aos processos mais eficientes em relação aos insumos (economia de matérias e energia) e obter conclusões por meio dos indicadores de emissões atmosféricas, verificando o quanto os biodigestores contribuíram positiva ou negativamente para essas emissões, principalmente em relação ao $\mathrm{CO}_{2 \mathrm{e}}$.

\section{Avaliação e Quantificação dos Indicadores por Empresa}

A Tabela 1 apresenta os valores antes e após a instalação dos equipamentos de aproveitamento de biogás para cada uma das empresas estudadas.

Tabela 1 - Consumo de lenha: indicador EN1

(materiais usados por massa e volume)

\begin{tabular}{|cccc|}
\hline Caso de estudo & $\begin{array}{c}\text { Amidonaria } \\
\text { C. Vale }\end{array}$ & $\begin{array}{c}\text { Amidos } \\
\text { Pasquini }\end{array}$ & $\begin{array}{c}\text { Alimentos } \\
\text { do Zé }\end{array}$ \\
\hline $\begin{array}{c}\text { Consumo médio diário de lenha antes do } \\
\text { aproveitamento do biogás }\end{array}$ & 32 toneladas & 18 toneladas & 9 toneladas \\
\hline $\begin{array}{c}\text { Consumo médio diário de lenha após apro- } \\
\text { veitamento do biogás }\end{array}$ & 9,6 toneladas & 0,9 toneladas & $\begin{array}{c}4,5 \text { tonela- } \\
\text { das }\end{array}$ \\
\hline $\begin{array}{c}\text { Percentual de economia do combustível } \\
\text { lenha com o aproveitamento do biogás }\end{array}$ & $70 \%$ & $95 \%$ & $50 \%$ \\
\hline $\begin{array}{c}\text { Quantidade média de mandioca moída dia- } \\
\text { riamente }\end{array}$ & 400 toneladas & 200 tonela- \\
das & 200 tone- \\
ladas
\end{tabular}

Fonte: Dados da pesquisa.

$\mathrm{Na}$ Tabela 1 verifica-se que a Amidos Pasquini teve a maior economia de combustível lenha com o aproveitamento do biogás nas caldeiras, com uma redução de $95 \%$ no consumo. O consumo residual de 4,5 kg é necessário 
para manter a chama-piloto da caldeira acesa. Já a Alimentos do Zé possui a menor taxa de economia (50\%). Provavelmente porque, entre outros fatores, a lagoa havia sido reformada poucos meses antes da pesquisa, havendo necessidade de maior tempo para que o processo de biodigestão se estabilize.

O próximo indicador ambiental analisado pela pesquisa é em relação ao consumo de energia direto por fonte de energia primária (EN3 e EN5). Eles permitiram a comparação entre a energia consumida com o combustível lenha antes e após o aproveitamento de biogás.

$\mathrm{Na}$ Tabela 2, verificam-se os volumes médios de lenha consumidos por empresa, assim como o valor numérico em quilocalorias dessa lenha. Com as quantidades de mandioca processadas por dia, foi calculado o consumo médio energético, em quilocalorias, para moagem de um quilo de mandioca, antes e após o aproveitamento do biogás nos biodigestores.

Tabela 2 - Energia derivada de lenha consumida por empresa por unidade de produção - indicador EN3

\begin{tabular}{|c|c|c|c|c|c|c|c|}
\hline \multirow[t]{2}{*}{ Empresa } & \multicolumn{2}{|c|}{$\begin{array}{l}\text { Lenha consumi- } \\
\text { da diariamente } \\
\text { média }(\mathrm{kg})\end{array}$} & \multicolumn{2}{|c|}{$\begin{array}{l}\text { Poder calorífico consu- } \\
\text { mido diariamente em } \\
\text { lenha (kcal) }\end{array}$} & \multirow{2}{*}{$\begin{array}{l}\text { Mandio- } \\
\text { ca moída } \\
\text { por dia } \\
(\mathrm{kg})\end{array}$} & \multicolumn{2}{|c|}{$\begin{array}{l}\text { Poder calorífico } \\
\text { consumido por } \\
\text { quilo de mandioca } \\
\text { moída (kcal) }\end{array}$} \\
\hline & $\begin{array}{c}\text { Antes } \\
\text { do } \\
\text { biogás }\end{array}$ & $\begin{array}{l}\text { Após } \\
\text { biogás }\end{array}$ & $\begin{array}{c}\text { Antes do } \\
\text { biogás }\end{array}$ & $\begin{array}{l}\text { Após } \\
\text { biogás }\end{array}$ & & $\begin{array}{l}\text { Antes } \\
\text { do } \\
\text { biogás }\end{array}$ & $\begin{array}{l}\text { Após } \\
\text { biogás }\end{array}$ \\
\hline C. Vale & 32.000 & 9.600 & 83.200 .000 & 24.960 .000 & 400.000 & 208 & 62,4 \\
\hline $\begin{array}{l}\text { Amidos } \\
\text { Pasquini }\end{array}$ & 18.000 & 900 & 43.200 .000 & 2.160 .000 & 200.000 & 216 & 10,8 \\
\hline $\begin{array}{c}\text { Alimentos } \\
\text { do Zé }\end{array}$ & 9.000 & 4.500 & 22.500 .000 & 11.250 .000 & 200.000 & 112 & 56 \\
\hline
\end{tabular}

Fonte: Dados da pesquisa.

O indicador EN5 mostra os valores economizados, em unidade energética, de combustível lenha, conforme Tabela 3. 
Segundo a GRI, o indicador EN5 visa a prover informações de economia e conservação de energia, com foco nas "melhorias tecnológicas e outras iniciativas de conservação de energia" (GLOBAL..., 2006a, p. 13). Observando-se os resultados da Tabela 3 , pode-se considerar que a tecnologia aplicada no aproveitamento do biogás trouxe resultados positivos.

Tabela 3 - Energia derivada de lenha economizada por empresa por unidade de produção com a recuperação e utilização do biogás produzido nas lagoas de estabilização - indicador EN5

\begin{tabular}{|c|c|c|c|c|c|}
\hline \multirow[b]{2}{*}{ Empresa } & \multirow[b]{2}{*}{ Combustível } & \multicolumn{2}{|c|}{$\begin{array}{l}\text { Poder calorífico consu- } \\
\text { mido por quilo de man- } \\
\text { dioca moída }\end{array}$} & \multirow{2}{*}{$\begin{array}{c}\text { Economia } \\
\text { em kcal por } \\
\text { tonelada de } \\
\text { mandioca } \\
\text { processada }\end{array}$} & \multirow[t]{2}{*}{$\begin{array}{c}\text { Economia } \\
(\%)\end{array}$} \\
\hline & & $\begin{array}{c}\text { Antes do } \\
\text { biogás }\end{array}$ & $\begin{array}{c}\text { Após o uso } \\
\text { do biogás }\end{array}$ & & \\
\hline C. Vale & Lenha & $208 \mathrm{kcal}$ & $62,4 \mathrm{kcal}$ & 145,6 & $70 \%$ \\
\hline Amidos Pasquini & Lenha & $216 \mathrm{kcal}$ & $10,8 \mathrm{kcal}$ & 205,2 & $95 \%$ \\
\hline Alimentos do Zé & Lenha & $112 \mathrm{kcal}$ & $56 \mathrm{kcal}$ & 56 & $50 \%$ \\
\hline
\end{tabular}

Fonte: Dados da pesquisa.

O indicador EN8 (água consumida por tonelada de mandioca processada antes e depois dos biodigestores), apesar de ser importante do ponto de vista ambiental para a cadeia de processamento de mandioca, não teve alteração nos valores, portanto não houve influência da instalação das coberturas nas lagoas de tratamento de efluentes na relação com consumo de água.

Com relação às emissões diretas de gases de efeito estufa por massa (EN16), a pesquisa obteve, por meio de medições efetuadas pela Planotec, os valores de biogás emitido no período de junho de 2013 a dezembro de 2013. Foi apurado o percentual de $\mathrm{CH}_{4}$ presente em cada medição. As mensurações ocorreram em um dia por mês, em cada uma das indústrias, duas vezes no dia.

A Tabela 4 apresenta os resultados médios dessas medições. Pode-se verificar que o teor de $\mathrm{CH}_{4}$ presente no biogás varia entre $55 \%$ e $60 \%$. Observa-se que a Alimentos do Zé, que tem a produção voltada quase que 
exclusivamente para farinha de mandioca, tem a geração na ordem de um terço de $\mathrm{CH}_{4}$ por tonelada de matéria-prima processada, quando comparada com a Amidos Pasquini, cujo produto é a fécula. Acredita-se que o motivo seja porque a produção de fécula gera maior quantidade de carga orgânica nos efluentes que a produção de farinha. O gestor da Alimentos do Zé relatou que, quando se produz polvilho (processo similar ao de fécula, com lavagem adicional da polpa da mandioca), foi observado aumento na geração de biogás.

Do ponto de vista de emissão de GEEs, a farinheira produz menor quantidade de $\mathrm{CO}_{2 \mathrm{e}}$ que as fecularias, por unidade de mandioca processada. Do ponto de vista econômico, porém, as fecularias mostraram-se mais satisfeitas com a instalação dos equipamentos para aproveitamento do biogás, pois geram maior economia de lenha, tendo maior redução dos custos do processo produtivo em relação à farinheira.

Tabela 4 - Geração média de biogás e percentual de metano - indicador EN16

\begin{tabular}{|c|c|c|c|c|c|}
\hline Empresa & $\begin{array}{c}\text { Toneladas de } \\
\text { mandioca moída } \\
\text { por hora na pro- } \\
\text { dução de fécula } \\
\text { e/ou farinha }\end{array}$ & $\begin{array}{c}\text { Produção mé- } \\
\text { dia de biogás } \\
\text { (normal metro } \\
\text { cúbico por } \\
\left.\text { hora }-\mathrm{nm}^{3} / \mathrm{h}\right)\end{array}$ & $\begin{array}{c}\% \text { mé- } \\
\text { dia de } \\
\mathrm{CH}_{4} \text { no } \\
\text { Biogás }\end{array}$ & $\begin{array}{c}\text { Produção } \\
\text { média } \\
\text { de } \mathrm{CH}_{4} \\
\text { por hora } \\
\left(\mathrm{nm}^{3} / \mathrm{h}\right)\end{array}$ & $\begin{array}{c}\mathrm{CH}_{4} \text { produzido } \\
\text { por tonelada } \\
\text { de mandioca } \\
\text { processada } \\
\left(\mathrm{nm}^{3} / \mathrm{h}\right)\end{array}$ \\
\hline C. Vale & 20 & 460 & $55,1 \%$ & 253 & 13 \\
\hline Amidos Pasquini & 10 & 340 & $55,4 \%$ & 188 & 19 \\
\hline Alimentos do Zé & 7,5 & 78,4 & $59,9 \%$ & 47 & 5 \\
\hline
\end{tabular}

Fonte: Dados da pesquisa.

A Tabela 5 apresenta a conversão das emissões diárias de $\mathrm{CH}_{4}$ em $\mathrm{CO}_{2}$ e (EN18) de acordo com a metodologia do Intergovernmental Panel on Climate Change (2007). Foram calculadas as emissões evitadas de $\mathrm{CO}_{2}$ e, considerando-se que, antes do sistema de aproveitamento do biogás, o $\mathrm{CH}_{4}$ era emitido livremente na atmosfera e, posteriormente, passou a ser consumido nas caldeiras. 
Tabela 5 - Geração média de $\mathrm{CH}_{4}$ e emissões de $\mathrm{CO}_{2 \mathrm{e}}$ evitadas com a queima do gás (EN18)

\begin{tabular}{|c|c|c|c|c|}
\hline Empresa & $\begin{array}{c}\text { Produção média } \\
\text { de } \mathrm{CH}_{4} \text { (normal } \\
\text { metro cúbico } \\
\text { por hora } \\
\left.\mathrm{nm}^{3} / \mathrm{h}\right)\end{array}$ & $\begin{array}{c}\text { Produção } \\
\text { média de } \mathrm{CH}_{4} \\
\text { por dia }(\mathrm{kg})\end{array}$ & $\begin{array}{c}\text { Emissões de } \\
\mathrm{CO}_{2 \mathrm{e}} \text { evitadas } \\
\text { com a queima } \\
\text { do } \mathrm{CH}_{4} \text { por dia } \\
\text { em toneladas }\end{array}$ & $\begin{array}{c}\text { Emissões de } \mathrm{CO}_{2 \mathrm{e}} \\
\text { evitadas com a } \\
\text { queima do } \mathrm{CH}_{4} \\
\text { por ano em tone- } \\
\text { ladas }\end{array}$ \\
\hline C. Vale & 253 & 3401 & 71 & 17.858 \\
\hline Amidos Pasquini & 188 & 2528 & 53 & 13.271 \\
\hline Alimentos do Zé & 47 & 630 & 13 & 3.309 \\
\hline
\end{tabular}

Fonte: Dados da pesquisa.

Na última coluna da Tabela 5 é possível verificar o total de emissões, em massa, de $\mathrm{CO}_{2 \mathrm{e}}$ que seriam emitidos em um ano, caso o biogás continuasse a ser dispersado sem a queima. Outras emissões indiretas também podem ser consideradas com a iniciativa, uma vez que lenha de plantações de eucalipto deixaram de ser usadas. Não foram computados, por exemplo, a necessidade de novas áreas para plantio, uso de combustiveis para transporte de madeira, entre outros.

O indicador EN20 é relativo às emissões do gás sulfídrico $\left(\mathrm{H}_{2} \mathrm{~S}\right)$. Esse gás pode ser prejudicial ao homem e ao meio ambiente: (i) causar irritações nos olhos e nariz e tonturas, diarreias, irritações no sistema respiratório e danos neurológicos (PRICE; CHEREMISINOFF, 1981); (ii) impactos ambientais relacionados à geração de chuva ácida e odor nas vizinhanças das indústrias. $\mathrm{O} \mathrm{H}_{2} \mathrm{~S}$ possui também a característica de ser corrosivo e poderá danificar equipamentos quando em contato direto.

Tabela 6 - Concentração de $\mathrm{H}_{2} \mathrm{~S}$ X tempo de exposição e efeitos

\begin{tabular}{c|c|c}
\hline $\begin{array}{c}\text { Concentração } \\
\mathbf{H}_{2} \mathbf{S}(\mathbf{p p m})\end{array}$ & $\begin{array}{c}\text { Tempo de } \\
\text { Exposição }\end{array}$ & Efeitos \\
\hline $0,0005-0,13$ & 1 minuto & percepção do odor \\
\hline $10-21$ & $6-7$ horas & irritação ocular \\
\hline $50-100$ & 4 horas & conjuntivite \\
\hline $150-200$ & $2-15$ minutos & perda do olfato \\
\hline
\end{tabular}




\begin{tabular}{c|c|c}
\hline 200-300 & 20 minutos & $\begin{array}{c}\text { inconsciência, hipotensão, edema pulmonar, convul- } \\
\text { são, tontura e desorientação }\end{array}$ \\
\hline 900 & 1 minuto & inconsciência e morte \\
\hline $1.800-3.700$ & instantes & morte \\
\hline
\end{tabular}

Fonte: LINS et al. (2005).

Na Tabela 6 pode-se observar possíveis riscos à saúde humana provocados pelo $\mathrm{H}_{2} \mathrm{~S}$, de acordo com sua concentração e o tempo de exposição. $\mathrm{Na}$ Tabela 7 verificam-se os valores médios, medidos nas empresas, de $\mathrm{H}_{2} \mathrm{~S}$ em partes por milhão (ppm). As medições compreenderam o período de junho de 2013 a dezembro de 2013, uma vez ao mês com duas medições.

Tabela 7 - Valores de $\mathrm{H}_{2} \mathrm{~S}$ mensurados no biogás gerado pelas lagoas de estabilização - indicador EN20

\begin{tabular}{cc} 
Empresa & $\mathbf{H}_{2} \mathbf{S}(\mathbf{p p m})$ média \\
C. Vale & 123,4 \\
Amidos Pasquini & 123,1 \\
Alimentos do Zé & 127,8 \\
\hline
\end{tabular}

Fonte: Dados da pesquisa.

Os valores das empresas estão muito próximos, pois o tipo de carga orgânica dos efluentes das três indústrias é similar. Comparando-se os valores da Tabelas 6 com os valores medidos da Tabela 7, verifica-se que as empresas deverão analisar a necessidade de instalação de sistemas de remoção do $\mathrm{H}_{2} \mathrm{~S}$ antes da queima do biogás.

Quanto ao impacto ambiental - o odor -, foram constatados, por meio das entrevistas, relatos diferenciados entre as empresas. A Amidonaria C. Vale declarou que o odor nunca foi um problema na planta ou na vizinhança. As outras empresas informaram que perceberam impacto positivo com a cobertura das lagoas, pois antes era perceptível o odor proveniente das lagoas e depois de cobertas resultou em significativa diminuição do cheiro. 
Outra melhora citada durante as entrevistas, porém não quantificada, foi a redução das emissões atmosféricas de material particulado (fuligem). Com a diminuição do uso de lenha, a fuligem gerada pela queima diminuiu, melhorando o desempenho ambiental do processo quanto ao aspecto, emissões atmosféricas de material particulado.

Quanto ao indicador EN21 relacionado aos efluentes descartados no meio ambiente, seja em cursos d'água ou diretamente no solo, não se conseguiu efetuar as medições necessárias para apurar os valores de DBO e DQO e calcular o indicador, portanto foram obtidos somente dados qualitativos por meio das entrevistas com os gestores. A C. Vale declarou que houve melhora considerável na qualidade dos efluentes e que, após a cobertura das lagoas, os parâmetros em relação ao DBO observados em auditorias legais permanceram com maior folga com a tecnologia do biodigestor. As outras duas empresas não souberam afirmar se houve alteração nos efluentes em decorrência das coberturas das lagoas.

\section{Considerações Finais}

Entre as empresas pesquisadas, a Amidos Pasquini conseguiu o máximo de economia com o aproveitamento do biogás, chegando a $95 \%$ na redução do uso de combustível (lenha). Os 5\% ainda são necessários para manter a acesa a chama-piloto do gás queimado na caldeira. A C. Vale é a única na pesquisa que possui sistema que detecta automaticamente e em tempo real a quantidade de combustível que deve ser injetado no processo, o que maximiza o aproveitamento do biogás. Observa-se que há potencial para melhorias tecnológicas no aproveitamento do biogás em empresas que alimentam o combustível nas caldeiras de forma manual, isto é, passar a utilizar a detecção automática de injeção de combustível.

Nesta pesquisa apresentou-se o poder calorífico consumido de lenha, antes e depois do aproveitamento do biogás, por quantidade de mandioca processada. Utilizando-se essa unidade de medidas foi possível comparar as 
empresas dentro dos mesmos valores relativos por quilo de mandioca processada. A Amidos Pasquini e Alimentos do Zé processam valores próximos (200 toneladas) de mandioca diariamente, com valores próximos de energia (216 e 112 kcal). Após o uso do biogás, entretanto, os valores são bastante diferentes $(10,8$ e $56 \mathrm{kcal})$ para o uso da lenha. O uso do biogás como fonte alternativa de energia diminuiu significativamente o emprego da madeira como forma de aquecimento das caldeiras.

Outro aspecto ambiental relevante para as indústrias pesquisadas é em relação ao consumo de água. Observou-se que não houve alteração nesse ponto quando se instalaram os biodigestores, não afetando o desempenho ambiental quanto a esse aspecto.

Provavelmente o aspecto ambiental mais importante avaliado foi a emissão de GEEs. Isso porque o $\mathrm{CH}_{4}$ era emitido livremente na atmosfera antes do aproveitamento do biogás nas caldeiras. Esse é, indiscutivelmente, de grande potencial para efeito de aquecimento global. A produção de farinha gera menor quantidade de GEEs, uma vez que para uma tonelada de mandioca processada, produzem-se $5 \mathrm{~nm}^{3} / \mathrm{h}$ de $\mathrm{CH}_{4}$, enquanto as fecularias produzem mais que o dobro dessa quantidade. Segundo Lybaek, Christensen e Kjaer (2013), a produção de biogás é um modo eficiente de reduzir as emissões de GEEs.

Em decorrência disso, é natural que a queima do biogás traga mais benefícios ambientais para as fecularias do que para as farinheiras. Isso é mostrado pelo indicador de emissões de $\mathrm{CO}_{2 \mathrm{e}}$ (evitados), derivado do $\mathrm{CH}_{4}$, em uma projeção de um ano de produção. Enquanto a empresa C. Vale, com a queima de biogás, evita emitir em torno de 18 mil toneladas, a Amidos Pasquini, pouco mais de 13 mil, e a Alimentos de Zé evita emitir pouco mais de 3 mil toneladas de $\mathrm{CO}_{2 \mathrm{e}}$ em forma de $\mathrm{CH}_{4}$ por ano. 
Outro indicador é relativo às emissões atmosféricas de $\mathrm{H}_{2} \mathrm{~S}-$ um gás tóxico que impacta o meio ambiente -, seja pela inalação direta por homens e animais, seja por meio das chuvas ácidas. Os resultados mostraram que os valores obtidos são de significância suficiente para que haja monitoramento constante desse indicador pelos gestores das empresas.

O último indicador representa a qualidade da água descartada pelas empresas. Conforme constatado na pesquisa, os efluentes das atividades processadoras de mandioca geram efluentes tóxicos ao meio ambiente. O que este trabalho não conseguiu obter, no entanto, foram dados para se comprovar tal questão.

De uma forma geral, a investigação apontou vários pontos que mostraram o desempenho ambiental favorável ao uso da tecnologia de aproveitamento do biogás em indústrias processadoras de mandioca, sejam elas fecularias ou farinheiras. Dentro dos limites desta pesquisa, é possível avaliar o desempenho ambiental do uso da tecnologia de aproveitamento energético de biogás, baseando-se nos indicadores GRI, apresentando as três empresas pesquisadas como indicadoras de resultados ambientais favoráveis.

Observou-se que o projeto de introdução da tecnologia na indústria processadora de mandioca tem alta flexibilidade, possibilitando a instalação de uma forma simples, com aproveitamento de equipamentos já existentes, como as caldeiras à base de combustível lenha, com poucas adaptações para uso do biogás, mas também podem ser adicionadas mais inovações tecnológicas, que requerem maior volume de investimentos, como é o caso do equipamento da C. Vale, que regula a quantidade de lenha necessária de acordo com a oferta de biogás em tempo real e automaticamente. Desse modo, observa-se que empresas de diferentes portes podem tirar vantagem dessa tecnologia para ter uma produção mais sustentável.

\section{Referências}

ABRAMOVAY, R. Muito além da economia verde. São Paulo: Abril, 2012. 
ARAUJO, J. B.; OLIVEIRA, J. F. G. Proposta de metodologia para a análise e seleção de indicadores para sistemas de avaliação de desempenho em sustentabilidade. In: WORKSHOP INTERNACIONAL DE PESQUISA EM INDICADORES DE SUSTENTABILIDADE. 2., 2008. São Carlos. Anais... São Carlos, SP: WIPS, 2008. ASSOCIAÇÃO BRASILEIRA DE NORMAS TÉCNICAS (ABNT). NBR ISO 14001: 2004 - Sistemas de Gestão Ambiental: requisitos com orientações para uso. Rio de Janeiro: ABNT, 2004.

BARANA, A. C.; CEREDA, M. P. Cassava wastewater (manipueira) treatment using a two-phase anaerobiv biodigestor. Ciência e Tecnologia de Alimentos, v. 20, n. 2, p. 183-186, 2000.

BARBIERI, J. C. Gestão ambiental empresarial. 2. ed. São Paulo: Saraiva, 2007.

BARBIERI, J. C. et al. Inovação e sustentabilidade: novos modelos e proposições. Revista de Administração de Empresas, v. 50, n. 2, p. 146-154, 2010.

BOONS, F.; BAUMANN, H.; HALL, J. Conceptualizing sustainable development and global supply chains. Ecological Economics, v. 83, p. 134-143, nov. 2012.

CAMPOS, A. T. et al. Tratamento de águas residuárias de fecularia por meio de lagoas de estabilização. Engenharia Agrícola, v. 26, n. 1, p. 235-242, jan./abr. 2006.

CENTRO DE ESTUDOS AVANÇADOS EM ECONOMIA APLICADA; ESCOLA SUPERIOR DE AGRICULTURA LUIZ DE QUEIROZ. Fécula de mandioca: produção na Tailândia versus Brasil. Piracicaba: Cepea; Esalq, 2013. Disponível em: <http://cepea.esalq.usp.br/pdf/Agroanalysis_marco_2013.pdf>. Acesso em: 24 abr. 2015.

C. VALE. Breve histórico C. Vale. Disponível em: <http://www.cvale.com.br/nossa_empresa.html>. Acesso em: 26 jul. 2014.

CREMONEZ, P. A. et al. Biodigestão anaeróbia no tratamento de água residuária de fecularia. Acta Igua u, v. 2, n. 2, p. 89-99, 2013.

CUNICO, E.; CIRANI, C. B. S.; SOUZA, M. T. S. D. Ecoinovação: implementação da tecnologia de biodigestores com desempenho ambiental. In: ENCONTRO NACIONAL SOBRE GESTÃO EMPRESARIAL E MEIO AMBIENTE, 14., 2012, São Paulo. Anais... São Paulo: Engema, 2012.

DELAI, I.; TAKAHASHI. S. Uma proposta de modelo de referência para mensuração da sustentabilidade corporativa. RGSA - Revista de Gestão Social e Ambiental, v. 2, n. 1, p. 19-40, 2008. 
DEMAJOROVIC, J.; MATURANA, L. M. Desenvolvimento de produtos sustentáveis: purificadores de água Brastemp e Carpetes Interface. RGSA - Revista de Gestão Social e Ambiental, v. 3, n. 3, p. 102-119, 2009.

FARIA, A. C.; NOGUEIRA, E. P. Sustentabilidade em instituições financeiras no Brasil: uma análise sob a ótica da Global Reporting Initiative - GRI. In: ENCONTRO NACIONAL DA ASSOCIAÇÃO DE PROGRAMAS DE PÓS-GRADUAÇÃO EM ADMINISTRAÇÃO, 35., 2011, Rio de Janeiro. Anais... Rio de Janeiro, 2011.

FELIPE, F. I.; RIZATO, M.; WANDALSEN, J. V. Potencial econômico dos resíduos de mandioca provenientes de fecularias no Brasil. In: CONGRESSO DA SOCIEDADE BRASILEIRA DE ECONOMIA, ADMINISTRAÇÃO E SOCIOLOGIA RURAL, 47., 2009. Porto Alegre. Anais... Brasília: Sober, 2009.

FELIPE, F. I.; ALVES, L. R. A.; CAMARGO, S. G. C. Panorama e perspectivas para a indústria de fécula de mandioca no Brasil. Revista Raíes e Amidos Tropicais, v. 6 , p. 134-146, 2010.

FOOD AND AGRICULTURE ORGANIZATION OF THE UNITED NATIONS. Save and grow: Cassava a guide to sustainable production intensification. Rome: FAO, 2013. Disponível em: <http://www.fao.org/docrep/018/i3278e/i3278e00.htm>. Acesso em: 24 jan. 2015.

FUCHS, W.; DROSG, B. Assessment of the state of the art of technologies for the processing of digestate residue from anaerobic digesters. Water Science \&̊ Tecnology, v. 67, n. 9, p. 1.984-1.994, 2013.

GALLOPÍN, G. C. Indicators and their use: Information for decision-making. In: MOLDAN, B.; BILLHARZ, S. Sustainability indicators. Wiley, 1997. Cap. 1. Disponível em: <http://www.scopenvironment.org/downloadpubs/scope58/ch01-introd. html>. Acesso em: 29 ago. 2011.

GLOBAL REPORTING INITIATIVE (GRI). Conjunto de protocolos de indicadores, 2006a. Disponível em: <http://www.globalreporting.org>. Acesso em: 18 jun. 2013.

. Diretrizes para relatório de sustentabilidade. Amsterdam: GRI, 2006b. Disponível em: <http://www.globalreporting.org>. Acesso em: 18 jul. 2013.

. What is GRI? Disponível em: <https:/www.globalreporting.org/information/ about-gri/what-is-GRI/Pages/default.aspx>. Acesso em: 15 abr. 2014. 
HEDBERG, C. J.; VON MALMBORG, F. The Global Reporting Initiative and corporate sustainability reporting in Swedish companies. Corporate Social Responsibility and Environmental Management, v. 10, n. 3, p. 153-164, 2003.

HODGE, M.; OCHSENDORF, J.; FERNÁNDEZ, J. Quantifying potential profit from material recycling: a case study in brick manufacturing. Journal of Cleaner Production, v. 18, n. 12, p. 1.190-1.199, 2010.

INÁCIO, R. O. et al. Desenvolvimento regional sustentável: abordagens para um novo paradigma. Desenvolvimento em Questão, v. 11, n. 24, p. 6-40, set./dez. 2013.

INTERGOVERNMENTAL PANEL ON CLIMATE CHANGE (IPCG). IPCC Fourth Assessment Report. Climate Change, 2007. Disponível em: <http://www.ipcc. ch/pdf/assessment-report/ar4/syr/ar4_syr_full_report.pdf >. Acesso em: 20 jul. 2014.

JAHN, T. G.; DADAM, A. P.; NICOLAU, V. P. Estudo da eficiência energética de forno a rolos. In: CONGRESSO BRASILEIRO DE CERÂMICA, 50, 2006, Blumenau. Anais... São Paulo: Abceram, 2006.

LINS, E. A. M. et al. Avaliação da insalubridade causada pelo biogás de um aterro de resíduos sólidos urbanos. In: CONGRESSO BRASILEIRO DE ENGENHARIA SANITÁRIA E AMBIENTAL, 23., 2005, Campo Grande. Anais... Rio de Janeiro, RJ: Abes, 2005.

LYBAEK, R.; CHRISTENSEN, T. B.; KJAER, T. Governing innovation for sustainable development in the Danish Biogas Sector - a historical overview and analysis of innovation. Sustainable Development, v. 21, n. 3, p. 171-182, 2013.

MARX, A. M.; PAULA, I. C. Proposta de uma sistemática de gestão de requisitos para o processo de desenvolvimento de produtos sustentáveis. Produção, v. 41, n. 3, p. 417-431, 2011.

MORI JR., R.; BEST, P. J.; COTTER, J. Sustainability reporting and assurance: a historical analysis on a worldwide phenomenon. Journal of Business Ethics, v. 120, n. 1, p. 1-11, 2014.

OLIVEIRA, K. R. F. D.; IDE, C. N.; PAULO, P. L. Processos ecotecnológicos no tratamento de efluentes líquidos de fecularia. CONGRESSO BRASILEIRO DE MANDIOCA. 11., 2005, Campo Grande. Anais... Brasília, DF: Embrapa, 2005.

PARIZOTTO, A. A. Minimização de custos econômicos e ambientais pelo uso de lagoas de sedimentação no tratamento de despejos de fecularias. Revista de Ciências Empresariais da Unipar, v. 3, n. 2, p. 211-218, 2002. 
PRICE, E. C.; CHEREMISINOFF, P. N. Biogas: production and utilization. Ann Arbor, Michigan, USA: Ann Arbor Science, 1981.

REZENDE, G. M.; ICHIKAWA, E. Y. O contexto ambiental e as mudanças organizacionais no setor de C\&'T agrícola do Paraná. Desenvolvimento em Questão, v. 9, n. 18, p. 111-138, 2011.

SANT'ANNA JR, G. L. Tratamento biológico de efluentes: fundamentos e aplicações. Rio de Janeiro: Interciência, 2010.

SEIFFERT, M. E. B. ISO 14001 Sistemas de gestão ambiental - implantação objetiva e econômica. 3. ed. São Paulo: Atlas, 2010.

SEIXAS, J.; FOLLE, S.; MARCHETTI, D. Construção e funcionamento de biodigestores. Brasília: Embrapa, 1980.

SERVIÇO NACIONAL DE APRENDIZAGEM INDUSTRIAL (Senai. RS). Implementação de programas de produção mais limpa. Porto Alegre: Centro Nacional de Tecnologias Limpas; Senai-RS/Unido/Inep, 2003.

SILVA, F.; SIQUEIRA, J. R. M.; GOMES, M. Z. A decomposição do modelo da Global Reporting Initiative (GRI) para avaliação de relatórios de sustentabilidade. Revista do BNDES, v. 34, p. 102, 2010.

STARR, K. et al. Life cycle assessment of biogas upgrading technologies. Waste Management, v. 32, n. 5, p. 991-999, 2012.

STOCCHETTI, A. The sustainable firm: from principles to practice. International Journal of Business Management, v. 7, n. 21, p. 34-48, 2012.

Recebido em: 17/7/2015

Aceito em: 7/4/2016 